\title{
Differential gene expression in response to cold stress in Viola wittrockiana
}

\author{
Ali Deljou ${ }^{1}$, Morteza Hosseini-Vasoukolaei ${ }^{1}{ }^{*}$, Samad Goudarzi ${ }^{1}$, Sommayeh Falahatian ${ }^{1}$,

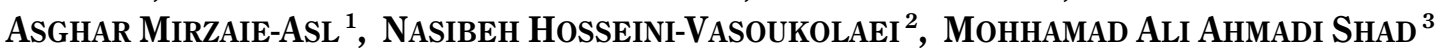 \\ ${ }^{1}$ Department of Biotechnology, Bu-Ali Sina University, Hamedan, Iran \\ ${ }^{2}$ Department of Medical Entomology and Vector Control, Health Sciences Research Center, Faculty of Health, \\ Mazandaran University of Medical Sciences, Sari, Iran \\ ${ }^{3}$ Department of Biotechnology, Faculty of Agriculture, University of Guilan, Rasht, Iran
}

\begin{abstract}
Environmental stresses such as cold are among the most important factors contributing to plant species diversity. When exposed to cold and freezing temperatures, most temperate plants enhance their tolerance prior to the arrival of sub lethal colds. This mechanism of plant adaptation in the face of cold stress conditions is called chilly acclimation. The purpose of this study was to gather more information about the genes involved in cold acclimation through the detection and isolation of differentially expressed transcripts in Viola wittrockiana plants under different temperature treatments. Changes in gene expression levels were studied using the differential display RT-PCR method (DDRT-PCR). Band separation was carried out in a 19\% non-denaturing polyacrylamide gel. In this study, six samples were isolated and sequenced. These sequences were screened for similarity with known sequences deposited in databases, using the BLAST algorithm. Also, the expression patterns of six newly-identified ESTs were confirmed by Northern blot analyzes. MHV2 and MHV6 showed significant homology to 23S rRNA and trnI-GAU genes, respectively.
\end{abstract}

Keywords: cold stress, differential display, gene expression, Viola wittrockiana

\section{Introduction}

Viola is an ornamental plant of the Violaceae family, which contains about 800 different species. One of its most important species is the hybrid Viola wittrockiana, a garden plant popular worldwide owing to its beautiful flowers and to its substantial cold resistance. Environmental stresses such as cold are among the most important factors contributing to plant species diversity. Most temperate plants, when exposed to cold and freezing temperatures, are able to enhance their tolerance prior to the arrival of sub lethal colds. This is a mechanism of plant adaptation in the face of cold stress conditions (chilly acclimation) (Chinnusamy et al., 2006). It has long been expected and now is well accepted that temperature acclimations are the result of complex processes, involving a number of physiological, biochemical and molecular changes. These include: modifications in membrane struc- ture and/or function, changes in global gene expression, or even in tissue water content. These changes may also occur in proteins when their structures have been altered, in membrane fluidity (the content and combinations of lipids), or primary and secondary metabolite compositions (Chinnusamy et al., 2007; Shinozaki and Dennis, 2003). During cold acclimation, there is also an induction of effector genes and heightened expression of transcriptional factors, which are known as cold-regulated (COR) genes (Bajwa et al., 2014; Viswanathan and Zhu, 2002; Xiong et al., 2002).

Recent advances in global gene expression analyzes and genome sequencing methods have allowed us to better understand the complex nature of temperature acclimation and the multigenic basis of responses to environmental stresses (Fowler and Thomashow, 2002; Kreps et al., 2002; Seki et al.,2001). Many studies have

* Corresponding author: Department of Biotechnology, Bu-Ali Sina University, Hamedan, Iran; e-mail: morzhossini@gmail.com 
reported direct effects of temperature on morphological, physiological and metabolic characteristics of Viola. For example, the optimum temperature for large flowers is between $18^{\circ} \mathrm{C}$ and $25^{\circ} \mathrm{C}$ and any increase in temperature beyond this level results in smaller flower size (Pearson et al., 1995). Moreover, at temperatures higher than $30^{\circ} \mathrm{C}$ the levels of glucose and sucrose in Viola decrease, as does the photosynthesis rate (Natarjan 2005). The purpose of this study was to gain more insight into the genes involved in cold acclimation through the detection and isolation of differentially expressed genes in Viola plants under cold stress conditions. To achieve this goal, we used the DDRT-PCR technique which, by means of PCR, is used to detect even small changes in mRNA content in cells and this is extensively used in plant research (Huang, 2007; Liang and Pardee, 1992). This method is also characterized by technical simplicity and flexibility, since it does not require any information on the RNA sequences of the organism of interest (Lang and et al., 2005; Wang and Feuerstein, 1997).

\section{Materials and methods}

\section{Plant material}

Seeds of Viola wittrockiana obtained from Benary Germany were sown in equal proportions of decayed animal manure, light soil and sand. Seed germination occurred after 1 month of incubation under greenhouse conditions. Due to the low germination rate and small seed size, the seeds were planted at a depth of less than $0.5 \mathrm{~cm}$. Two months after germination, pots were transferred into growth chambers and used for cold treatments. After adaptation of the plants to the new environment, the growth room temperature was adjusted to $25^{\circ} \mathrm{C}$ (control), and $5^{\circ} \mathrm{C}, 0^{\circ} \mathrm{C},-5^{\circ} \mathrm{C}$ or $-10^{\circ} \mathrm{C}$ (stress treatments), each for 72 hours, at a photoperiod of $16 \mathrm{~h}: 8 \mathrm{~h}$ with 2000 lux light intensity. At the end of each treatment, middle leaves of plants were sampled and stored at $-80^{\circ} \mathrm{C}$ for RNA extraction.

\section{RNA isolation and differential display RT-PCR}

Equal amounts (20 g) of fresh leave tissues collected from plants grown in every treatment condition (stressed and control) were used for total RNA extraction using an RNeasy Plant mini kit (Qiagen, Hilden, Germany). Extracted RNA samples were subjected to DNA
Table 1. Sequences of eight $5^{\prime}$-arbitrary primers used in DDRT-PCR amplification

\begin{tabular}{c|c}
\hline Arbitrary Primer Name & Sequence $\left(5^{\prime}-3^{\prime}\right)$ \\
\hline HAP25 & AAGCTTTCCTGGA \\
HAP26 & AAGCTTGCCATGG \\
HAP27 & AAGCTTCTGCTGG \\
HAP28 & AAGCTTACGATGC \\
HAP29 & AAGCTTAGCAGCA \\
HAP30 & AAGCTTCGTACGT \\
HAP31 & AAGCTTGGTGAAC \\
HAP32 & AAGCTTCCTGCAA \\
\hline
\end{tabular}

digestion using an RNAse-Free DNAse kit (Qiagen). The quantity and quality of RNA samples was measured via UV Spectrophotometer at $260 \mathrm{~nm}$ (Eppendorf Company, Germany) and electrophoresis in 1\% agarose gel. The cDNAs were synthesized via a Bio-RT Two Step RT-PCR kit (Qiagen). Three sets of $3^{\prime}$-oligo(dt) anchored primers - 5'-AAGCTTTTTTTTTTTG-3' ${ }^{\prime} 5^{\prime}$-AAGCTTTTTTTTT TTC- $3^{\prime}$ and $5^{\prime}$-AAGCTTTTTTTTTTTA- $3^{\prime}$ - were used in combination with one of eight $5^{\prime}$-arbitrary primers for PCR amplification (Table 1). Amplification of cDNA was performed using an Eppendorf thermal cycler with the following programming: initial denaturation at $94^{\circ} \mathrm{C}$ for 5 min, followed by 35 cycles of 30 seconds at $94^{\circ} \mathrm{C}$ (denaturation), $1 \mathrm{~min}$ at $40^{\circ} \mathrm{C}$ (annealing), 90 seconds at $72^{\circ} \mathrm{C}$ (extension) and $10 \mathrm{~min}$ at $72^{\circ} \mathrm{C}$ (final extension). The quality of PCR products was confirmed by electrophoresis in $2 \%$ agarose gel, and the products were then separated on non-denaturing polyacrylamide gel (19\%). The gels were prepared based on the modified Boschi and Vergara (1998) protocol. The vertical electrophoresis apparatus was manufactured by Paya Pajoohesh Company, Iran.

\section{Silver staining}

Silver staining was performed according to the protocol described by Sambrook et al. (1989), with minor changes. Throughout this staining procedure, the gel was shaken on a rotary shaker at $70 \mathrm{rpm}$. In the first step, it was dipped in the fixer buffer (30\% ethanol, $10 \%$ acetic acid, $60 \% \mathrm{H}_{2} \mathrm{O}$ ) for 30 minutes, followed by two times washing in $\mathrm{ddH}_{2} \mathrm{O}$. In the next step, it was dipped in $1 \%$ silver nitrate solution for 20 minutes. Finally, after washing with $\mathrm{ddH}_{2} \mathrm{O}$, the gel was developed in a developer solution ( $3 \% \mathrm{NaOH}, 38 \%$ formaldehyde). 


\section{Cloning and analysis of DNA fragments}

The differential bands obtained from the amplification of cDNA fragments were cut from the gels, transferred into Eppendorf tubes containing $50 \mathrm{ml}$ of nuclease-free water and incubated at $40^{\circ} \mathrm{C}$ for $2 \mathrm{~h}$. The gel debris was spinned down for $10 \mathrm{~s}$ and the supernatants (containing DNA sequences) were collected in new tubes (Caamal et al., 2007). The DNA fragments were reamplified using the same set of primers as previously. The amplification was performed in an Eppendorf thermal cycler under the following conditions: initial denaturation at $94^{\circ} \mathrm{C}$ for $5 \mathrm{~min}$, followed by 35 cycles of $30 \mathrm{~s}$ at $94^{\circ} \mathrm{C}$ (denaturation), $1 \mathrm{~min}$ at $40^{\circ} \mathrm{C}$ (annealing), $90 \mathrm{~s}$ at $72^{\circ} \mathrm{C}$ (extension) and $10 \mathrm{~min}$ at $72^{\circ} \mathrm{C}$ (final extension). Re-amplified PCR products were ligated directly into a PCR-Trap vector (Gen Hunter Corporation) and then transformed into Escherichia coli GH-competent cells (Gen Hunter Corporation). Transformation was performed according to the manufacturer's instructions. The PCR-Trap cloning vector contains a gene carrying a resistance to tetracycline antibiotic and allows for the selection of recombinant plasmids containing colonies from the non-recombinant ones. The presence of cDNA inserted fragments was confirmed by PCR techniques using Lgh and Rgh primers (left and right sequencing, respectively, Gen Hunter) and these were constructed to flank the blunt-ended ligation points. Fragments of cDNA were isolated from the PCR-Trap vector by a HindIII restriction digest and sequenced with Lgh and Rgh sequencing primers (Gen Hunter). To determine the sequence alignments, the BLAST search program and DNA STAR software were used (www.ncbi.nlm. nih.gov).

\section{Northern blot assay}

Equal amounts of total RNAs ( $20 \mu \mathrm{g})$ from every tested condition were separated on $1.2 \%$ Agarose gels containing $1.2 \%$ formaldehyde. After the electrophoresis, RNA was transferred into positively charged nylon membranes (Amersham Hybond $\mathrm{N}+$ membrane). Prior to hybridization, the blots were incubated in $10 \mathrm{ml} \mathrm{FSB}$ buffer (100 mM tetra-sodium pyrophosphate, $50 \mathrm{mM}$ sodium phosphate, $1 \mathrm{mM}$ EDTA) containing 7\% SDS and $1 \mathrm{mM}$ fish sperm (heat-denatured) at $65^{\circ} \mathrm{C}$ for $1 \mathrm{~h}$. Hybridization was performed in the same conditions (at $65^{\circ} \mathrm{C}$ for $1 \mathrm{~h}$ ) with the addition of a cDNA probe that was radio

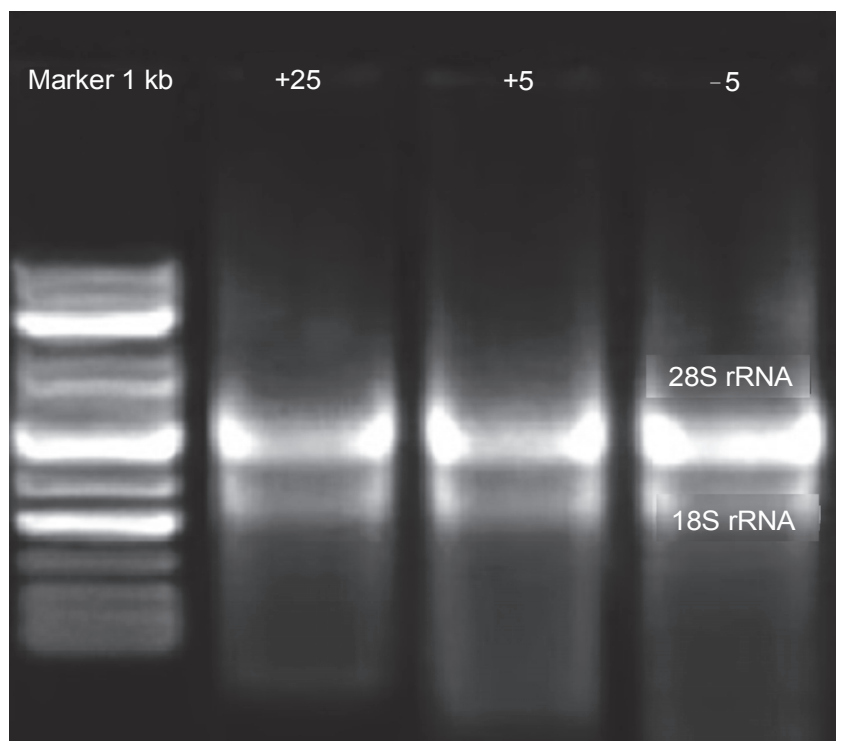

Fig. 1. Comparison of total RNA extraction from leaves of Viola wittrockiana grown in three temperature conditions $\left(+25^{\circ} \mathrm{C},-5^{\circ} \mathrm{C}, 5^{\circ} \mathrm{C}\right)$

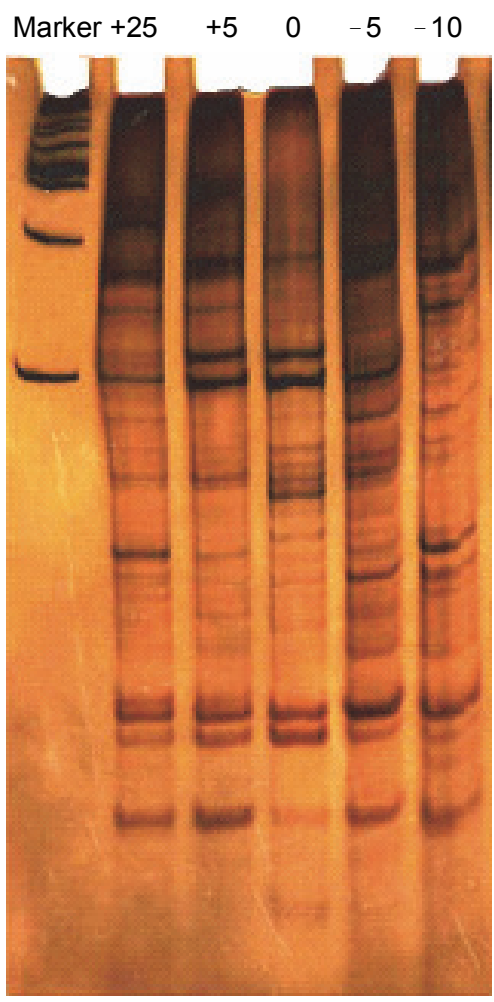

Fig. 2. Example of an mRNA differential display (DDRT-PCR) from Viola wittrockiana $\left(+25^{\circ} \mathrm{C},+5^{\circ} \mathrm{C}, 0^{\circ} \mathrm{C},-5^{\circ} \mathrm{C},-10^{\circ} \mathrm{C}\right.$ ) (primers used: oligo dT-G and HAP29). The DNA fragments were separated in a19\% polyacrylamide gel and stained with silver nitrate. DNA marker size range: $1 \mathrm{~Kb}$ DNA marker (Bioneer)

labeled using the $\mathrm{dCTP}$ random primer-marking technique. After this step, membranes were washed in a wa- 
shing A-buffer containing $2 \times \mathrm{SSC}, 0.1 \%$ SDS at room temperature for $20 \mathrm{~min}$ and then washed in two other washing buffers - B-buffer containing: $1 \times$ SSC, $0.1 \%$ SDS and C-buffer containing: $1 \times \mathrm{SSC}, 0.5 \% \mathrm{SDS}-$ at $65^{\circ} \mathrm{C}$ for $45 \mathrm{~min}$ each. The blots were exposed to the X-ray films (Kodak X-Omat Blue).

\section{Results and discussion}

\section{Evaluation of the performance of primers}

Total RNA was extracted with a high quality and quantity. It was used to produce cDNA (Fig. 1). From the cDNA, using eight 5 '-arbitrary primers (Table 1 ), the differentiating PCR products representing different cold stress treatments were amplified (Fig. 2). The bands obtained from Viola wittrockiana treated with five cold temperature treatments were compared. In general, under the $-5^{\circ} \mathrm{C}$ treatment conditions we were able to obtain more bands (519) than from plants stressed with other temperatures (from 410 to 479 ) - Figure 3. In the reverse transcription reaction, three types of oligo-dT primers anchored with $\mathrm{C}, \mathrm{G}$ or $\mathrm{A}$ were used. The results showed that, among these three primers, oligo-dT-C and -G gave rise to more bands than the oligo-dT-A primer (Fig. 4). The results obtained for PCR experiments with the eight arbitrary primers described previously are shown in Figure 5. The most efficient primer (based on the number of bands) was HAP30 and the least efficient one was HAP25 (Fig. 5). The result of this study was similar to the results of Caamal et al. (2007), where the authors investigated the differences in gene expression between banana plants under cold stress conditions. Their experiments demonstrated that the combination of particular primers (HAP25 to HAP32), oligo-dT-G, HAP30 and HAP31 gave rise to many more bands than any other combination of primers.

\section{mRNA differential display RT-PCR and northern blot assay}

On the basis of the number of bands obtained in PCR reactions, three anchored primer combinations, from amongst the eight arbitrary primers, produced 51 differential bands from the Viola wittrockiana plants (the number of differentiating bands was based on visual observations). From this number, six differential bands were selected (these sequences showed clearer visual differences than the others) for cloning and sequencing.

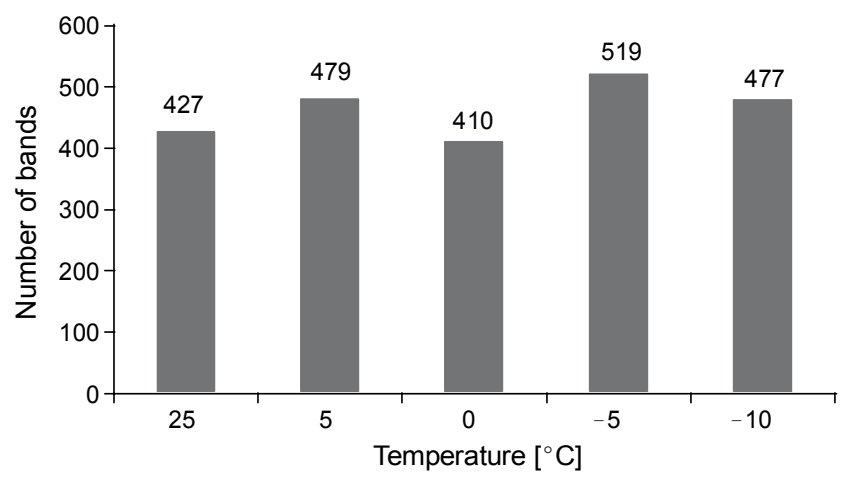

Fig. 3. The numbers of bands obtained using the DDRT-PCR method from five temperature treatments in Viola Wittrockiana.

The highest number of bands was produced at $-5^{\circ} \mathrm{C}$

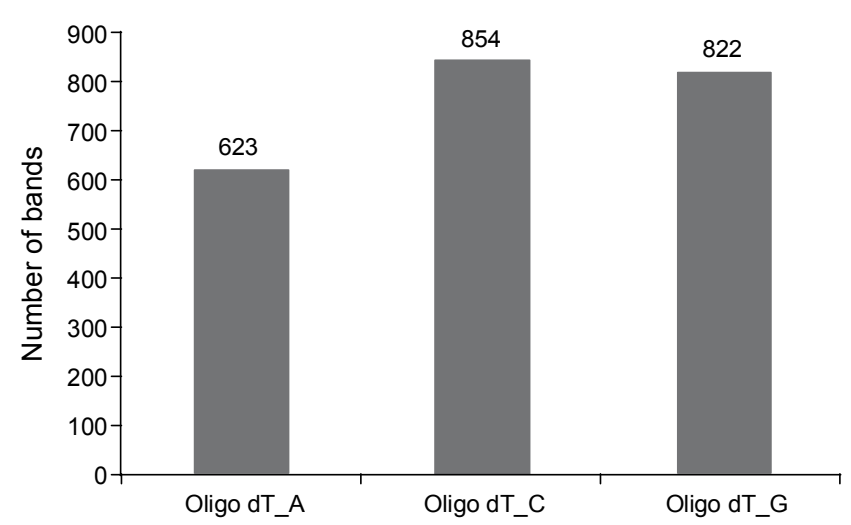

Fig. 4. The number of bands from five temperature treatments produced using different primers (3 Oligo-dT). The primer Oligo dT-C gave rise to more bands than others; Oligo dT-A produced the smallest number of bands

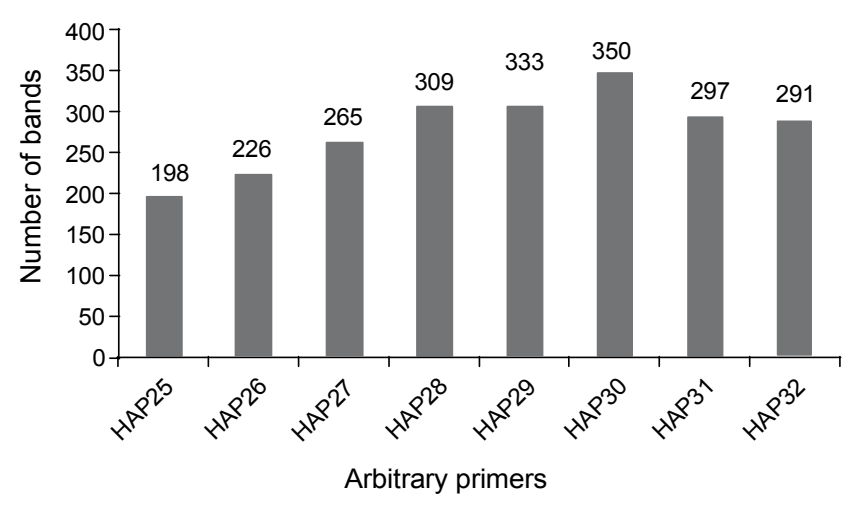

Fig. 5. The number of bands produced using different arbitrary primers (between three Oligo-dT primers and five temperatures). The HAP30 created the greatest and the HAP25 the lowest amount of bands

Ten clones obtained from each band were randomly selected and the cloned inserts were sequenced. Also, the expression pattern of 6 ESTs (selected based on the DDRT-PCR technique) was confirmed by the Northern blot analysis. This showed that the level of expression 

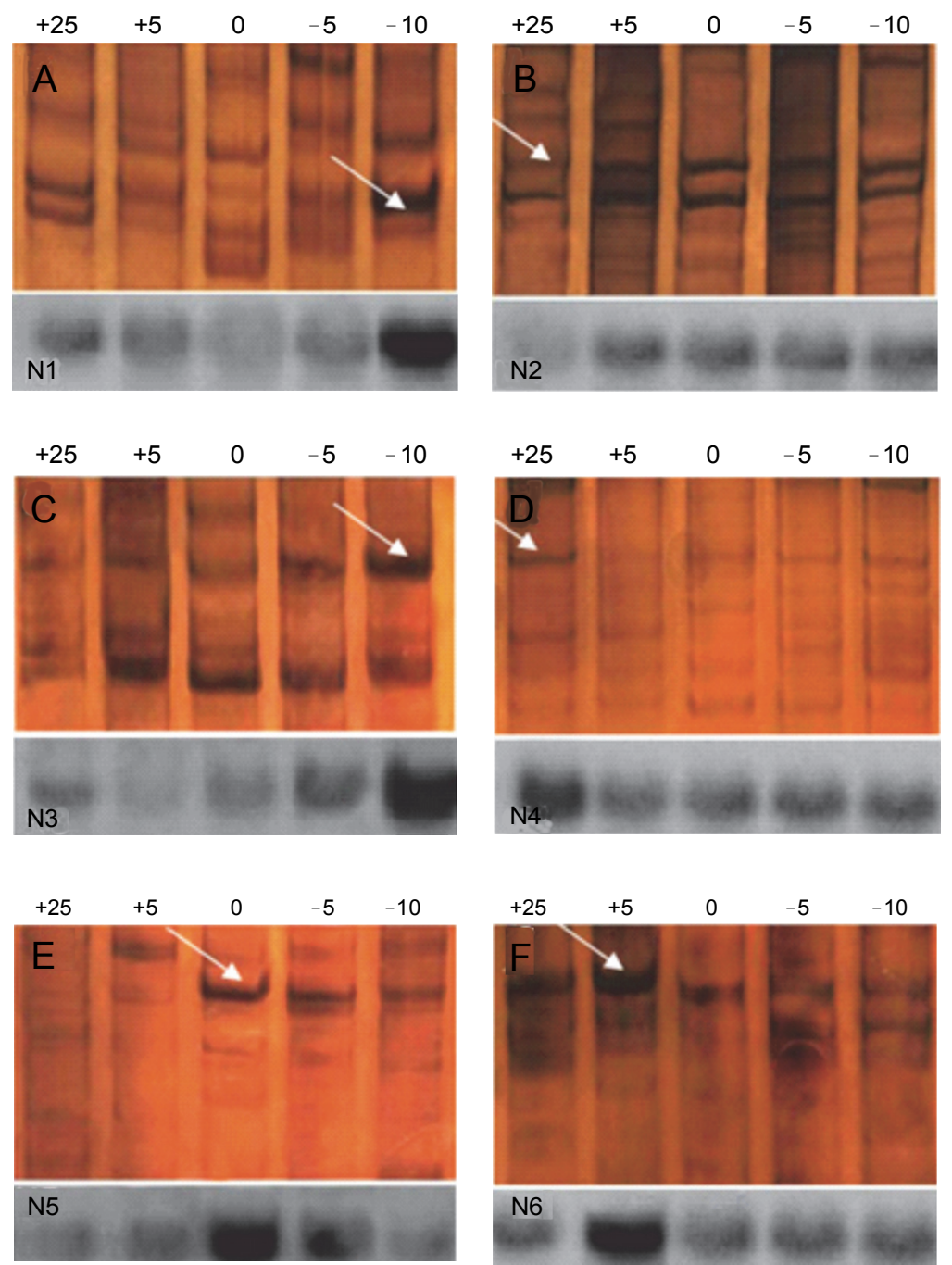

Fig. 6. Six differentialbands chosen for sequencing (sequence names): A) MHV1, B) MHV2, C) MHV3, D) MHV4, E) MHV5, F) MHV6) expressed at different temperatures (at the top of each gel) in Viola wittrockiana. Below each picture of differential bands from DDRT-PCR electrophoresis results of Northern blot assays (N1: MHV1, N2: MHV2, N3: MHV3, N4: MHV4, N5: MHV5, N6: MHV6) with confirmation of differential expression of selected sequences in Viola wittrockiana under cold stress conditions are shown

of those DNA fragments was differentially induced by cold treatment. Furthermore, it could be seen that not all sequences expressed under cold stress conditions were affected to the same degree (Fig. 6). Among the six selected sequences, three showed the highest expression below $0^{\circ} \mathrm{C}$ (Fig. $6 \mathrm{~A}-\mathrm{C}$ ), two showed the most distinct induction of expression above $0^{\circ} \mathrm{C}$ (Fig. $6 \mathrm{D}$ and $6 \mathrm{~F}$ ) and finally expression of only one sequence was strongly induced at $0^{\circ} \mathrm{C}$ (Fig. $6 \mathrm{E}$ ).

\section{Sequence analysis of differentially displayed cDNA fragments}

A sequence analysis of the cDNAs obtained using the DDRT-PCR technique from Viola wittrockiana led to the differentiation of 51 differential cDNA fragments, of which six were sequenced and analyzed further. The sequences were recorded in the EST database of NCBI (Table 2).

The results of bioinformatic analyzes of selected sequences are summarized in Table 2 . The sequences labeled MHV1, MHV3, MHV4 and MHV5 showed no significant homology with DNA or protein sequences deposited in NCBI databases. For further evaluation of four unknown sequences, we used other software such as Uniport, DNA STAR and CLC MainWorkbench 5.5, but unfortunately the E-value scores were still too high and therefore unreliable. There was no significant information about these sequences in any database, so we con- 
Table 2. Identification, analysis and EST records obtained from the cDNA of Viola wittrockiana subjected to cold stress conditions, using BLAST algorithm

\begin{tabular}{c|c|c|c|c|c|c}
\hline $\begin{array}{c}\text { Sequence } \\
\text { name }\end{array}$ & Gen bank ID & $\begin{array}{c}\text { Size } \\
\text { (nt) }\end{array}$ & Homologous gene & $\begin{array}{c}\text { E-value } \\
\text { score }\end{array}$ & $\begin{array}{c}\text { Identification } \\
(\%)\end{array}$ & $\begin{array}{c}\text { Accession } \\
\text { number }\end{array}$ \\
\hline MHV1 & JZ084082 & 293 & none significant & $\begin{array}{c}\text { none } \\
\text { significant }\end{array}$ & $\begin{array}{c}\text { none } \\
\text { significant }\end{array}$ & $\begin{array}{c}\text { none } \\
\text { significant }\end{array}$ \\
\hline MHV2 & JZ084083 & 243 & 23 rRNA from Salixbabylonica chloroplast DNA & $1 \mathrm{e}-96$ & $98 \%$ & KP861984.1 \\
\hline MHV3 & JZ084084 & 784 & none significant & none & $\begin{array}{c}\text { none } \\
\text { significant }\end{array}$ & $\begin{array}{c}\text { none } \\
\text { significant } \\
\text { significant }\end{array}$ \\
\hline MHV4 & JZ084085 & 824 & none significant & none & none & none \\
significant & nonificant & significant \\
\hline MHV5 & JZ084086 & 69 & none significant & none & none \\
significant & significant & significant \\
\hline MHV6 & JZ084087 & 177 & trnI-GAU gene from Viola seoulensis plastid & 5e-64 & $92.5 \%$ & KP749924.1 \\
\hline
\end{tabular}

cluded that the four displayed sequences (MHV1, MHV3, MHV4, and MHV5) had been identified for the first time. However, two remaining sequences, namely MHV2 and MHV6, showed significant homology (98\%)to 23S rRNA from the Salix babylonica chloroplast (Accession number: KT449800.1) and homology (92.5\%) to trnI-GAU gene from plastid DNA of Viola seoulensis (Accession number: KP749924.1). The MHV2 sequence also showed 98\% similarityto the 23S rRNA gene from a hybrid cultivar of a Populus tree (Populustremula $\times$ Populusalba) isolated under drought stress conditions (EST registered in NCBI with accession number: CU227874.1). The presence of ribosomal RNAs constituting large ribosomal subunits could be related to the increased protein production rate. Since the bands of the MHV2 sequence showed a higher expression level at lower temperature (Fig. 6B), it is possible that a particular protein or group of proteins is being produced under the cold stress conditions in chloroplasts. In a study on tobacco plants under cold stress conditions, it was shown that the presence of Rpl33 is important in cold acclimation. Rpl33 is a ribosomal protein that is produced in chloroplasts. It was found that when Rpl33 is knocked out, this does not affect plant viability and growth under standard conditions, whereas exposure of mutant tobacco plants to low temperature stress causes severe abnormalities (Rogalski et al., 2008). Also, Coetzer et al. (2010) reported a 23SrRNA gene (EST: GR942609.1) that is expressed in chloroplasts of cowpea under drought conditions. It has been shown that stress conditions such as salinity, drought and high/low tem- peratures may evoke similar effects on the plant cellular functions. Therefore, in some cases, the damage inflicted by these stress conditions can be very similar (Wang et al., 2003). Abiotic stresses including drought, salinity and freezing temperatures can affect normal cellular functions in different ways. The most common effects of these stresses lead to a loss of turgor pressure, which can cause the destruction of cell membranes and protein structures. Moreover, in most cases the simultaneous production and accumulation of excessive levels of reactive oxygen species causes additional oxidative damage. As a consequence, oxidative destruction leads to the inhibition of photosynthesis and cellular metabolism, reduced growth and premature senescence (Krasensky and Jonak, 2012). Generally, there are complex relationships between molecular regulation and gene expression involved in cold acclimation, because most of these processes include an extensive network of molecular interactions.

The sequence of MHV6 shows a similarity to trnIGAU gene that encodes the isoleucyl-tRNA (tRNA-Ile). tRNA-Ile carries the amino acid isoleucine to the ribosome during protein biosynthesis. This sequence was present in all of the five temperature treatments, but its expression level at $+5^{\circ} \mathrm{C}$ was much higher than at other tested temperatures (Fig. 6F). On the assumption that the existence of tRNA-Ile is related to the presence of isoleucine in cells, Mayer et al. (1990) showed that the rate of isoleucine synthesis increased up to 6-fold in cowpea plants under heat shock conditions. Also, it has been found that the presence of compounds such as jasmo- 
noyl-isoleucine is required to synthesize abscisic acid (ABA) in Arabidopsis thaliana roots under drought stress conditions (Ollas et al., 2015). ABA is a growth regulator which is known to be responsive to osmotic and cold stresses in plants (Ishitani et al., 1997). In another study on Bacillus subtilis, it was shown that isoleucine played a major role in cold resistance and the absence of isoleucine reduced the synthesis of anteiso-branched fatty acids that build membranes (Klevin et al., 1999). Generally, membranes need lipids for the stabilization of their structure and function, so it is important to have an appropriate lipid composition and therefore physical state of membranes. The membrane lipids change their structure in response to cold temperatures in order to maintain the fluidity of membranes. For example, Bacillus cells avoid the damage inflicted at low temperatures by increasing the amount of low-melting-point fatty acids in their plasma membrane (Mansilla et al., 2004; Cybulski et al., 2002). Therefore, changes in membrane fluidity can be considered a basic concept of the membrane responses under cold stress conditions. Perhaps there are certain groups of lipids with a high degree of saturation in the plasma membrane of $V$. wittrockiana cells which can protect the membrane under cold stress conditions. Although the experiments conducted on plants have emphasized that membrane lipid fluidity has a direct influence on plant resistance to cold stress conditions (Ishitani et al., 1998; Miquel et al., 1993; Murata et al., 1992), it is still not well understood whether there is any correlation between membrane fluidity and cold responsive genes.

\section{Conclusion}

Our experiments clearly showed that there are significant differences between gene expression patterns in control $\left(25^{\circ} \mathrm{C}\right)$ temperature and low $\left(<25^{\circ} \mathrm{C}\right)$ temperature treatments. Some of the bands from DDRT-PCR indicate higher levels of expression of particular DNA fragments at certain temperatures. The expression of genes observed in our experiments as differential bands at a given temperature is probably related to genes that are directly or indirectly involved in chilling resistance. However, in order to achieve a deeper understanding of the molecular mechanisms of cold resistance in Viola and other plant species that are tolerant to cold, more experiments should be conducted and more genes isolated and sequenced.

\section{Acknowledgement}

The authors are thankful to the Department of Biotechnology, Shahid Beheshti University of Iran and the Department of Biotechnology, Bu-Ali Sina University of Iran for providing necessary facilities. This study was financially supported by the Department of Biotechnology, Bu-Ali Sina University, Iran.

\section{References}

Bajwa V.S., Shukla M.R., Sherif S.M. et al. (2014) Role of melatonin in alleviating cold stress in Arabidopsis thaliana. J. Pineal Res. 56: 238-245.

Boschi E., Vergara M.R. (1998) A protocol for nonradioactive differential display tested on carrot auxin-resistant $m u$ tants. Plant Mol. Bio. Rep. 16: 1-18.

Caamal-Velazquez J.H., Chi-Manzanero B.H., Canche-Yam J.J. et al. (2007) Low temperature induce differential expression genes in banana fruits. Sci. Hortic. 114: 88-89.

Chinnusamy V., Zhu J., Zhu J.K. (2006) Gene regulation during cold acclimation in plants. Acta Physiol. Plant. 126: $52-61$.

Chinnusamy V., Zhu J., Zhu J.K. (2007) Cold stress regulation of gene expression in plants. Trends Plant Sci. 12: 444451.

Coetzer N., Gazenda I., Oelofse D., Berger D.K. (2010) SSHscreen and SSHdb, generic software for microarray based gene discovery: application to the stress response in cowpea. Plant Meth. 6(10): doi: 10.1186/1746-4811-6-10.

Cybulski L.E., Albanesi D., Mansilla M.C., et al. (2002) Mechanism of membrane fluidity optimization: isothermal control of the Bacillus subtilis acyl lipid desaturase. Mol. Microbiol. 45: 1379-1388.

Fowler S., Thomashow M.F. (2002) Arabidopsis transcriptome profiling indicates that multiple regulatory pathways are activated during cold acclimation in addition to the CBF cold response pathway. Plant Cell. 14: 1675-1690.

Huang H. (2007) Research advances and application of DDRTPCR in plant research. J. Anhui Agricult. Sci. 35: 1307.

Ishitani M., Xiong L., Lee H., et al. (1998) HOS1, a genetic locus involved in cold-responsive gene expression in Arabidopsis. Plant Cell 10: 1151-1161.

Ishitani M., Xiong L., Stevenson B., Zhu J.K. (1997) Genetic analysis of osmotic and cold stress signal transduction in Arabidopsis: interactions and convergence of abscisic acid-dependent and abscisic acid-independent pathways. Plant Cell. 9: 1935-1949.

Klein W., Weber M.H., Marahiel M.A. (1999) Cold shock response of Bacillus subtilis: isoleucine-dependent switch in the fatty acid branching pattern for membrane adaptation to low temperatures. J. Bacteriol. 181: 5341-5349.

Krasensky J., Jonak C. (2012) Drought, salt, and temperature stress-induced metabolic rearrangements and regulatory networks. J. Exp. Bot. 63: 1593-1608.

Kreps J.A., Wu Y., Chang H.S., et al. (2002) Transcriptome changes for Arabidopsis in response to salt, osmotic, and cold stress. Plant Physiol. 130: 2129-2141. 
Lang P., Zhang C.K., Ebel R.C., et al. (2005) Identification of cold acclimated genes in leaves of Citrus unshiu by $m R N A$ differential display. Gene 359: 111-118.

Liang P., Pardee A.B. (1992) Differential display of eukaryotic $m R N A$ by means of the polymerase chain reaction. Science 257: 967-971.

Mansilla M.C., Cybulski L.E., Albanesi D., de Mendoza D. (2004) Control of membrane lipid fluidity by molecular thermosensors. J. Bacteriol. 186: 6681-6688.

Mayer R.R., Cherry J.H., Rhodes D. (1990) Effects of heat shock on amino acid metabolism of cowpea cells. Plant Physiol. 94: 796-810.

Miquel M., James D., Dooner H. (1993) Arabidopsis requires polyunsaturated lipids for low-temperature survival. Proc. Natl. Acad. Sci. 90: 6208-6212.

Murata N., Ishizaki-Nishizawa O., Higashi S., Hayashi H., Tasaka Y., Nishida I. (1992) Genetically engineered alteration in the chilling sensitivity of plants. Nature 356: 710713.

Natarjan S. (2005) High temperature stress responses of Salvia splendens and Viola wittrockiana. Thesis for the degree of Phd. in horticulture. Acharya N.G. RangaAgri University.

Ollas C., Arbona V., Gomez-Cadenas A. (2015) Jasmonoylisoleucine accumulation is needed for abscisic acid build up in roots of Arabidopsis under water stress conditions. Plant Cell Environ. 38: 2157-2170.

Pearson S., Parker A.N.N., Adams S.R., et al. (1995) The effects of temperature on the flower size of pansy (Viola $x$ wittrockiana). J. Hortic. Sci. Biotechnol. 10: 183-190.
Rogalski M., Schöttler M.A., Thiele W., Schulze W.X., Boc R. (2008) Rp133, a nonessential plastid-encoded ribosomal protein in tobacco, is required under cold stress conditions. Plant Cell. 20: 2221-2237.

Sambrook J., Fritsch E.F., Maniatis T. (1989) Molecular Cloning: A Laboratory Manual. Cold Spring Harb. Lab Press. Cold Spring Harbor NY, USA.

Seki M., Narusaka M., Abe H., et al. (2001) Monitoring the expression pattern of 1300 Arabidopsis genes under drought and cold stresses by using a full-length cDNA microarray. Plant Cell. 13: 61-72.

Shinozaki K., Dennis E.S. (2003) Cell signalling and gene regulation: global analyzes of signal transduction and gene expression profiles. Curr. Opin. Plant Biol. 6: 405-409.

Viswanathan C., Zhu J.K. (2002) Molecular genetic analysis of cold-regulated gene transcription. Pill. Trans. R. Soc. B. 357: 877-886.

Wang W., Vinocur B., Altman A. (2003) Plant responses to drought, salinity and extreme temperatures: towards genetic engineering for stress tolerance. Planta 218: 1-14.

Wang X., Feuerstein G.Z. (1997) The use of mRNA differential display for discovery of novel therapeutic targets in cardiovascular disease. Cardiovasc. Res. 35: 414-421.

Xiong L., Schumaker, K.S., Zhu J.K. (2002) Cell signaling during cold, drought, and salt stress. Plant Cell. 14: 165-183. 